\title{
Pattern of drug utilization in pediatric out patient department of a tertiary care teaching hospital
}

\author{
Rekha M. B.*, Hemamalini M. B., Basavaraj Bhandare
}

Department of Pharmacology, RRMCH, Bangalore, Karnataka, India

Received: 18 February 2020

Revised: 13 October 2020

Accepted: 14 October 2020

\section{*Correspondence:}

Dr. Rekha M. B.,

Email: dr.rekhamb@gmail.com

Copyright: () the author(s), publisher and licensee Medip Academy. This is an open-access article distributed under the terms of the Creative Commons Attribution Non-Commercial License, which permits unrestricted non-commercial use, distribution, and reproduction in any medium, provided the original work is properly cited.

\begin{abstract}
Background: Drug utilization studies have special significance among paediatric age groups as infant and children represent about $42 \%$ of the population in developing countries. This is the vital period of rapid growth and development. Therefore, drugs should be used very cautiously and rationally among these sub groups. The present study is conducted to analyse the prescribing pattern of drugs in paediatric age group for various illnesses.

Methods: It was a prospective observational study, conducted in paediatric outpatient department of Raja Rajeswari medical college and research hospital for a period of 6 months after obtaining approval from institutional ethical committee. Descriptive statistical was used to determine the frequency, percentages, mean and standard deviation.

Results: In the present study, fever (30.8\%) followed by respiratory diseases were most common diseases seen. The commonly used drugs include antipyretics (66\%), antimicrobials (53.6\%), cough syrups (34.4\%), antihistaminic (31.2\%) and nasal decongestants (23.2\%). Prescribing indicator shows existence of polypharmacy. Prescribing drugs by generic name was seen only in $8.1 \%$ and $47.82 \%$ of the drugs were prescribed from EDL. The frequency of use of injectables in our study was $5.8 \%$.

Conclusions: Irrational use of antibiotics and polypharmacy needs to be curbed. Prescribing drugs in their generic name and prescribing drugs from EDL need to be promoted. The present prescribing pattern can be improved by advocating rational drug prescribing, patient education and improving hospitals.
\end{abstract}

Keywords: Prescribing, Pediatric, Outpatient, Tertiary care

\section{INTRODUCTION}

In recent years, drug utilization studies are found to be useful tool to facilitate rational use of drugs in health care systems. ${ }^{1}$ It truly reflects the status of health care system. In order to be rational, use of a drug must be effective, safe, prescribed for the proper therapeutic indication and correct dosage in an appropriate formulation, easily available and of a reasonable cost. The ultimate goal is to achieve rational and cost effective medical care. ${ }^{2,3}$
Drug utilization studies have special significance among paediatric age groups as infant and children represent about $42 \%$ of the population in developing countries. ${ }^{4}$ This is the vital period of rapid growth and development. Therefore, drugs should be used very cautiously and rationally among these sub groups. Besides, due to economic and ethical issues children do not often participate in clinical trials and specific knowledge about effect of drugs in children is often inadequate. While a large number of drug utilization studies are available for adults all over the world, a very few studies provide information on drug use pattern in paediatrics. ${ }^{5,6}$ 
Infants and children suffer from frequent but usually non serious illnesses and infections. ${ }^{7}$ Most of these are self limiting and are often treated not only inappropriately but also resorting to poly pharmacy. ${ }^{8,9}$ Prescribers need to take into account the way disposition of drugs in children differs from adult both pharmacokinetically and pharmacodynamically. ${ }^{10}$ For the rational prescribing of medicines in paediatric age, the first model list of essential drugs for children ( $<12$ years) was released in October 2007. It is aimed to serve as guidelines for rational prescribing in this age group. ${ }^{11,12}$

The present study is conducted to analyse the prescribing pattern of drugs in paediatric age group for various illnesses. The information is expected to aid in interventions that would improve the prescribing pattern and rational drug use in children.

\section{Objective}

Objective of the current study was to analyze the pattern of drug usage in paediatric outpatient department of a tertiary care teaching hospital.

\section{METHODS}

It was a prospective observational study, conducted in paediatric outpatient department of Raja Rajeswari medical college and research hospital for a period of 6 months from February 2018 to July 2018 after obtaining approval from institutional ethical committee.

Prescriptions given to paediatric patients for various diseases by paediatrician were collected. Patient related parameters such as age, sex and body weight were recorded. The drug data such as name of the drug, dosage form, dosing duration, route of administration and diagnosis were collected in the proforma. Informed consent was taken by the concerned parent/guardian.

Inclusion criteria: Inclusion criterion for the current study was all children attending pediatric outpatient department.

Exclusion criteria: Exclusion criterion for the current study was pediatric patients whose guardians did not give informed consent.

\section{Statistical analysis}

The data obtained were computed using Ms-Excel. The data was analyzed by using SPSS version 20. Descriptive statistical was used to determine the frequency, percentages, mean and standard deviation.

\section{RESULTS}

Results of total 250 prescriptions were collected and analysed. In the present study, it was seen that majority of the study population belonged to the age group 1-5 years
$(56 \%)$. It was seen that maximum prescriptions were for boys $(66 \%)$.

Table 1: Age distribution of study population.

\begin{tabular}{|ll|}
\hline Age (years) & $\mathbf{N}(\%)$ \\
\hline $\mathbf{0 - 1}$ & $70(28)$ \\
\hline $\mathbf{1 - 5}$ & $140(56)$ \\
\hline $\mathbf{5 - 1 2}$ & $40(16)$ \\
\hline
\end{tabular}

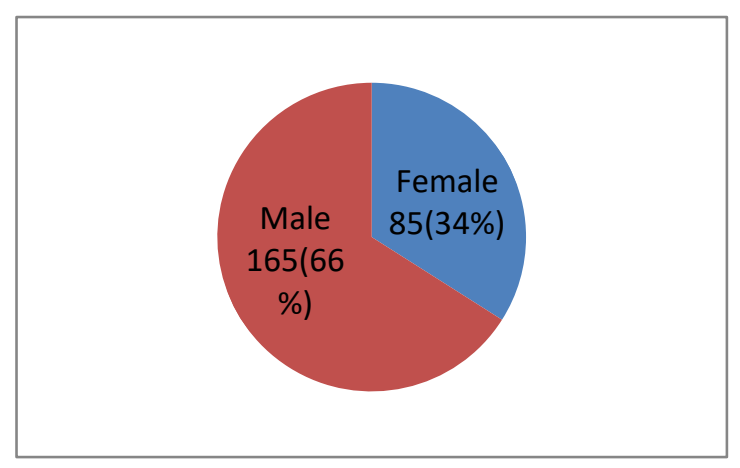

Figure 1: Gender distribution.

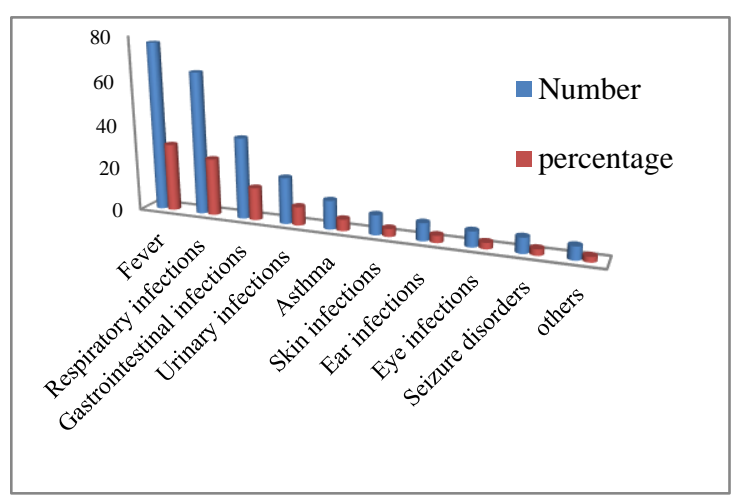

Figure 2: Disease distribution.

Looking into the disease distribution, fever (30.8\%) was the most common complaint as this could because viral fever is more common among children. The next common was respiratory diseases $(26 \%)$.

It was found that antipyretics $(66 \%)$ were most commonly used to treat fever. As paracetamol is the safest in children it was the antipyretic commonly used. Antimicrobials $(53.6 \%)$ were the next most common drugs used.

Antibiotic groups commonly used were penicillins (36\%) followed by cephalosporins $(25 \%)$ as they are the safest among children. Aminoglycosides were the least used antimicrobial agents.

Looking at the prescribing indicators it was seen that average number of drugs per prescription was $5.1 \%$. Prescribing drugs by generic name was seen only in $8.1 \%$ and $47.82 \%$ of the drugs were prescribed from EDL. The frequency of use of injectables in our study was $5.8 \%$. 
Table 2: Various classes of drugs prescribed.

\begin{tabular}{|ll|}
\hline Drug classes & $\mathbf{N}(\%)$ \\
\hline Antipyretics & $165(66)$ \\
\hline Cough syrups & $86(34.4)$ \\
\hline Antihistaminic & $78(31.2)$ \\
\hline Bronchodilators & $45(18)$ \\
\hline Steroids & $12(4.8)$ \\
\hline Antimicrobials & $134(53.6)$ \\
\hline Gastrointestinal drugs & $37(14.8)$ \\
\hline Vitamin preparations & $21(8.4)$ \\
\hline Antiepileptic drugs & $7(2.8)$ \\
\hline Nasal decongestants & $58(23.2)$ \\
\hline Others & $19(7.6)$ \\
\hline
\end{tabular}

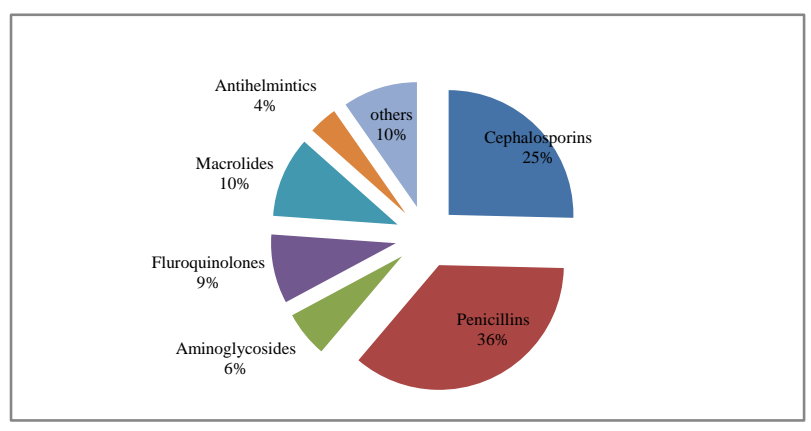

Figure 3: Various groups of antibiotics prescribed.

Table 3: Prescribing indicators.

\begin{tabular}{|l|l|}
\hline Indicators & Data (\%) \\
\hline $\begin{array}{l}\text { Average number of drugs per } \\
\text { encounter }\end{array}$ & 5.1 \\
\hline Drugs prescribed by generic name & 8.1 \\
\hline $\begin{array}{l}\text { Drugs prescribed from essential drug } \\
\text { list }\end{array}$ & 47.82 \\
\hline Encounters with injections & 5.8 \\
\hline Encounters with antibiotics & 53 \\
\hline
\end{tabular}

\section{DISCUSSION}

In the present study, it was seen that majority of the study population belonged to the age group $1-5$ years $(56 \%)$. This could be because children belonging to this group are more vulnerable and exposed to infections as they start their schooling at this age. It was also seen that maximum prescriptions were for boys $(66 \%)$ similar to other study as it is a known fact that compared to girls, boys are more prone for diseases. It could be also because of gender bias in getting treatment for girl child which is still prevalent in India. ${ }^{2}$

As we look into the disease distribution, fever (30.8\%) was the most common complaint as this could because viral fever is more common among children. The next common was respiratory diseases $(26 \%)$ which include upper respiratory infections, Bronchitis, Pneumonia.
Respiratory infections are common in this age group as the immune system is not very well developed.

It was found that antipyretics $(66 \%)$ were most commonly used to treat fever. As paracetamol is the safest in children it was the antipyretic commonly used. Antimicrobials (53.6\%) were the next most common drugs used to treat respiratory, urinary, gastrointestinal, eye and ear infections. As most of the infections in children are viral, use of antibiotics is unjustifiable. If antibiotics are not used cautiously it would result in antibiotic resistance and add also add burden to the patients. Hence antibiotics should be rationally used. Antibiotic groups commonly used were penicillins followed by cephalosporins as they are the safest among children. Use of aminoglycosides was also seen in the study population. Aminoglycosides should be judiciously used as it is ototoxic and nephrotoxic. Use of fluroquinolones in children can cause damage to the cartilage hence they should be carefully used in growing children. The other group of drugs commonly used were cough syrups (34.4\%), antihistaminic (31.2\%) and nasal decongestants $(23.2 \%)$ which were used to treat respiratory infections which were one of the most common diseases seen in our study population.

Looking at the prescribing indicators it was seen that average number of drugs per prescription was $5.1 \%$ which shows the existence of polypharmacy. Finding was similar to a previous study by Rajesh et al. ${ }^{4}$ Polypharmacy would result in unnecessary cost burden on patients, unwanted side effects, drug interactions and poor patient compliance. Hence it needs to be curbed. This is possible by making proper diagnosis. Prescribing more drugs to satisfy patients should also be avoided.

Prescribing drugs by generic name was seen only in $8.1 \%$ and $47.82 \%$ of the drugs were prescribed from EDL which is not a good indicator of rational prescription. It was observed that inclination to brand name prescribing was more. Provision of drugs in their generic name, prescribing from EDL and rational drug prescribing of drugs are recognized measures that can considerably reduce cost of the drugs to patients without a fall in treatment standards. The frequency of use of injectables in our study was 5.8\%. Prescribing injections would add more burden to patient hence they should be used only when needed.

\section{Limitations}

Limitations of current study were, the study was conducted in a single centre and prescription analysis was limited only to outpatient department.

\section{CONCLUSION}

Upon overall analysis it was found that, in the study population children in the age group of 1-5 years were more prone for diseases with male preponderance. Fever 
and respiratory diseases were the most common illnesses seen. Use of antibiotics was more which needs to be taken care. There is polypharmacy seen which needs to be curbed. Prescribing drugs in their generic name and prescribing drugs from EDL need to be promoted. The present prescribing pattern can be improved by advocating rational drug prescribing, patient education and improving hospitals.

Funding: No funding sources

Conflict of interest: None declared

Ethical approval: The study was approved by the Institutional Ethics Committee

\section{REFERENCES}

1. Gupta M, Safhi MM, Sumail JMY, Agarwal M. Prescribing pattern in children registered in the department of paediatrics of Jizan general hospital of Jizan, KSA. Int J Pharm Pharm Sci. 2013;5(4):397-9.

2. Akhtar MS, Vohora D, Pillai KK, Dubey K, Roy MS, Najmi AK, et al. Drug prescribing practices in paediatric department of a north Indian university teaching hospital. Asian J Pharm Clin Res. 2012;5 (1):146-9.

3. Antonio C, Maurizio B. Drug prescriptions to outpatient children: a review of the literature. Eur $\mathrm{J}$ Clin Pharmacol. 2009;6(5):749-55.

4. Suman RK, Mohanty NC, Mohanty IR, Deshmukh YA. The study of drug usage patterns in pediatric patients at MGM hospital, Navi Mumbai. World J of Pharm Res.2014;3(4):734-43.
5. Cazzato T, Pandolfini C, Campi R, Bonati M. Drug prescribing in out-patient children in Southern Italy. Eur J Clin. Pharmacol. 2001;57:611-6.

6. Kumar AM, Thulasi KR, Ramasamy C. Cross sectional prospective study on drug utilization in an outpatients pediatrics department of tertiary care teaching hospital. Global J Pharmacol. 2013;7(2):99102.

7. Ghai OP, Paul VK. Rational drug therapy in pediatric practice. Ind Pediatr. 1988;25:1095-109.

8. Sanz E, Boada J. Drug utilization in pediatric outpatients in Tenerife Island. Eur J Clin Pharmacol.1988;34:495-9.

9. Straand J, Rokstad K, Heggedal U. Drug prescribing for children in general practice: a report from the more and romsdal prescription study. Acta Pediatrica.1998;87:218-4.

10. Mirza NY, Desai S, Ganguly B. Prescribing pattern in a pediatric out-patient department in Gujarat. Bangladesh J Pharmacol. 2009;4:39-42.

11. Pandey AA, Thakre SB, Bhatkule PR. Prescription analysis of pediatric outpatient practice in nagpur city. Indian J Community Med. 2010;35(1):70-3.

12. WHO model list of essential medicines for children. Available at: https://www.who.int/medicines/ publications/essentialmedicines/en/. Accessed on 20 January 2020.

Cite this article as: Rekha MB, Hemamalini MB, Bhandare B. Pattern of drug utilization in pediatric out patient department of a tertiary care teaching hospital. Int J Basic Clin Pharmacol 2020;9:1661-4. 